\title{
Cervical Dysplasia and Human Papillomavirus in Women of the Republic of Sakha (Yakutia)
}

\author{
Maria P. Kirillina, $\mathrm{PhD}^{1,2^{*}}$; Irina V. Kononova, $\mathrm{PhD}^{1}$; Sargylana I. Sofronova, $\mathrm{PhD}^{1}$; \\ Matrena N. Mikhailova'; Varvara A. Vorontsova ${ }^{3}$; Elena L. Lushnikova, PhD, ScD ${ }^{4}$ \\ ${ }^{1}$ Yakut Science Centre of Complex Medical Problems, Yakutsk, Russia \\ ${ }^{2}$ M. K. Ammosov North-Eastern Federal University, Yakutsk, Russia \\ ${ }^{3} O O O$ "MALEX”, Yakutsk, Russia \\ ${ }^{4}$ Federal Research Center of Fundamental and Translational Medicine, Novosibirsk, Russia
}

\begin{abstract}
The purpose of this study was to investigate the relation between the presence of cervical dysplasia and HPV infection in women of the Republic of Sakha (Yakutia) (RS(Y)), to analyze cytological samples for detecting the presence of pathology and the degree of cervical dysplasia, and to detect the level of HPV infection, and establish the dependence of HPV-test positivity on the presence of dysplasia and the woman's age.

Methods and Results: Cytological material was taken from cervix uteri and cervical canal scraping from 100 patients aged between 22 and 60 years (mean age of $38.9 \pm 9.2$ years). The sample from every patient was obtained by traditional cytology and liquid-based cytology (LBC). The results of LBC were interpreted under the terminology system of the Bethesda System (2015). HPV detection and typing were performed by real-time PCR using commercial test systems according to their instructions.

The analysis of cytological samples by the LBC method in women of RS(Y) revealed a high prevalence of NILM in the samples to compare with intraepithelial lesions of the cervix. Among intraepithelial lesions, LSIL was significantly more common. Positive HPV tests were observed in less than half of the cases. The vast majority of positive HPV tests were high-risk HPV types, and 16 and 51 types marked the most frequent. The positive tests for high-risk HPV types in women with NILM and intraepithelial lesions (LSIL, HSIL, ASCUS) were approximately equal. The frequency of positive tests for high-risk HPV types in women under 45 was higher than in women 46 years and older.

Conclusion: The combined use of LBC and HPV testing for high-risk HPV infection improves the effectiveness of diagnostics by reducing the amount of uninformative material and allows detecting pathological changes at an earlier stage. (International Journal of Biomedicine. 2020;10(2):165-168.)
\end{abstract}

Key Words: human papillomavirus $\bullet$ cervical cancer $\bullet$ liquid-based cytology $\bullet$ squamous intraepithelial lesion

\section{Abbreviations}

ASCUS, atypical squamous cells of undetermined significance; CC, cervical cancer; CIN, cervical intraepithelial neoplasia; HPV, human papillomavirus; hrHPV, high-risk HPV; HSIL, high-grade SIL; LBC, liquid-based cytology; NILM, negative for intraepithelial lesion or malignancy; PCR, polymerase chain reaction; SIL, squamous intraepithelial lesion; LSIL, low-grade SIL

\section{Introduction}

HPV is one of the most common causes of sexually transmitted diseases. It is believed that more than $50 \%$ of

*Corresponding author: Maria P. Kirillina, PhD. Yakut Science Centre of Complex Medical Problems, Yakutsk, Russia. E-mail: kirillinamp@mail.ru sexually active women have encountered not only one but several more types of HPV. ${ }^{(1)}$ Epidemiological and molecularbiological data indicate an important role of HPV in the occurrence of cervical intraepithelial neoplasia (CIN) and cervical cancer (CC). Currently, it is generally accepted that $\mathrm{HPV}$ is one of the major factors in the development of CC. According to Wheeler et al., 3 years after HPV infection, CIN2-3 develops one in four women. ${ }^{(2)}$ 
HPVs can infect basal epithelial cells of the skin or inner lining of tissues and are categorized as cutaneous types or mucosal types. HPVs contain a 7.9-kb circular double-stranded DNA genome that consists of four parts: an early region (E1, 2, 4-7 genes), a late region (L1, 2 genes), a long control region (LCR), and a small, highly variable, non-coding region (NCR) between E5 and L2. ${ }^{(3)}$ To date, more than 200 types of HPVs have been well characterized, ${ }^{(4)}$ more than 40 of which can affect the mucous membranes of the genital organs. ${ }^{(5)}$

Based on their association with cervical cancer and precursor lesions, HPVs can also be grouped into high-risk (16 , 18,31,33,35,39,45,46,51,52,53,56,58,59,66,68,73,82) and lowrisk $(6,11,40,42,43,44,54,61,70,72,82)$ HPV types. ${ }^{(6-9)}$ Low-risk HPV types generally cause benign lesions of the cervix and condyloma. ${ }^{(10)}$

HPV affects the basal layer of the epithelium, where cell division is most active. Koilocytes are the predominant cellular features of infection with HPV. Later, under the influence of the immune system, the virus can be eliminated from the body. In the case of long-term persistence, HPV-DNA fits into the cell genome with subsequent step-by-step transformation of the epithelium up to the formation of cancer cells. ${ }^{(11)}$

The incidence of HPV infection is the highest in the age group of $15-19$ years: About $40 \%$ of positive tests of this group indicate the presence of HPV-DNA in the material taken from the cervix. The greater the age of women surveyed, the greater the decrease in the percentage of positive results: in the age group of $20-24$ year-olds, there are more than $30 \%$ with positive results; in the group of 25-29 year-olds, there are fewer than $30 \%$ positive. In the group of women who have reached the 30-year mark, there is a further decrease in the frequency of HPV infections to $15 \%-17 \%$. In women after menopause, HPV infection is very rare but has an important prognostic value due to the risk of developing malignant cervical pathology. In young women, HPV infection is mostly transient, while infection in postmenopausal women usually has the character of a long-term persistent infection. This is very dangerous for molecular changes that lead to the initiation of the process of carcinogenesis. ${ }^{(12)}$

Given the high prevalence of $\mathrm{CC}$, which is ranked the third most prevalent cancer in the world among women of reproductive age, ${ }^{(2)}$ the diagnosis of precancerous cervical pathology at the stage of intraepithelial neoplasia is an urgent global need. Currently, the development of methods and systems for early diagnosis of CIN is a top priority for healthcare. For the early diagnosis of CIN, the cytological method and molecular methods for detecting HPV-DNA are widely used. ${ }^{(13,14)}$ Molecular biology studies are direct methods for detecting HPV infection and have a significantly higher sensitivity than indirect method-cytological research. Currently, the highest sensitivity for detecting HPV infection belongs to the PCR method, in which the theoretical limit of recognition is a genomic copy per 100,000 cells. ${ }^{(15)}$ The combination of the HPV test and the cytological method has a higher predictive value for detecting CIN than a single HPV test. ${ }^{(16-18)}$

The purpose of this study was to investigate the relation between the presence of cervical dysplasia and HPV infection in women of the Republic of Sakha (Yakutia) (RS(Y)), to analyze cytological samples for detecting the presence of pathology and the degree of cervical dysplasia, and to detect the level of HPV infection, and establish the dependence of HPV-test positivity on the presence of dysplasia and the woman's age.

\section{Materials and Methods}

The study was conducted in the laboratory of pathomorphology, histology and cytology of the NEFU Medical Institute. Cytological material was taken from cervix uteri and cervical canal scraping from 100 patients aged between 22 and 60 years (mean age of $38.9 \pm 9.2$ years) after examination and extended colposcopy in the "Malex+" clinic (Yakutsk, Russia). The sample from every patient was obtained by traditional cytology and LBC on the automated system CellPrep Plus (Korea). The Romanovskiy-Gimza stain method was used. The results of LBC were interpreted under the terminology system of the Bethesda System, ${ }^{(19)}$ which includes NILM, LSIL (encompassing: HPV/mild dysplasia/ CIN 1), and HSIL (encompassing: moderate and severe dysplasia, CIS; CIN 2 and CIN 3).

HPV detection and typing (types 6, 11, 44, 16, 18, 26, $31,33,35,39,45,51,52,53,56,58,59,66,68,73$, and 82) were performed by real-time PCR using commercial test systems according to their instructions. The study data- the incidence of intraepithelial lesions of the cervix in the samples and the level of HPV infection among the examined womenare presented in the form of proportions (percent).

The study was carried out in compliance with Ethical Principles for Medical Research Involving Human Subjects, Adopted by the 18th WMA General Assembly, Helsinki, Finland, June 1964, and amended by the 59th WMA General Assembly, Seoul, Republic of Korea, October 2008. The study was approved by the Ethics Committee of the Yakut Science Center of Complex Medical Problems. Written informed consent was obtained from all participants.

Statistical analysis was performed using the statistical software «Statistica» (v. 13.0, StatSoft, USA). The frequencies of categorical variables were compared using the Chi-square test. A probability value of $P<0.05$ was considered statistically significant.

\section{Results and Discussion}

Assessing the levels of background and precancerous pathology by the LBC method, the absence of intracellular lesions were detected in $66 / 66 \%$ cases, of which $26 \%$ of patients had no pathology and $40 \%$ had reactive changessquamous metaplasia, inflammation, moderate hyperplasia (no significant differences were obtained). In general, including reactive changes, cervical pathology during LBC was detected in $74 / 74 \%$ cases. LSIL and HSIL were detected in $34 / 34 \%$ cases. LSIL was detected in 27 cases $(79.4 \%$ of all intraepithelial lesions), of which CIN1 in 20 cases (58.8\% of all intraepithelial lesions) cases and CIN1 with coilocytes in 7 cases ( $20.6 \%$ of all intraepithelial lesions) $(P=0.006)$. HSIL was recognized in 6 cases and accounted for $17.6 \%$ of the total 
number of dysplasias in the study group. Differences were statistically significant between the frequency of occurrence of LSIL and HSIL $(P=0.006)$. In $1(2.9 \%)$ case, ASC-US was diagnosed (Fig.1).

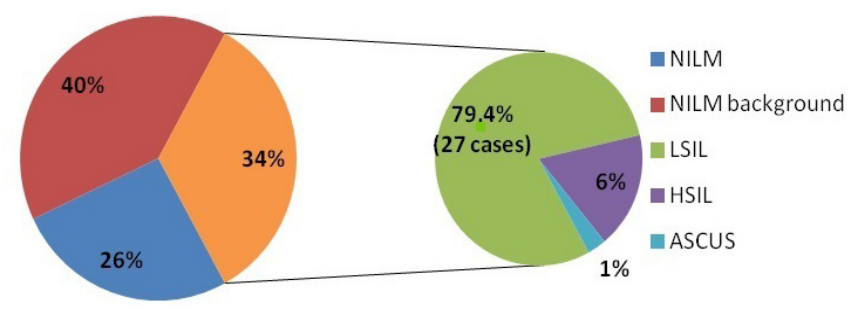

Fig.1. Structure of detected precancerous lesions of the cervix by $L B C$.

Forty-seven (47\%) women were tested for HPV, of which 19(40.4\%) were confirmed to have HPV. The presence of high-risk HPV types was significantly more common in 17 women ( $89.47 \%$ of all positive HPV tests) $(P<0.001)$. Of these, 8 women were diagnosed with NILM ( $47 \%$ of all positive tests for high-risk HPV types) and 9 with intraepithelial lesions (53\% of all positive tests for high-risk HPV types) $(P>0.72)$. In turn, the distribution of positivity for high-risk HPV types in women with intraepithelial lesions was carried out as follows: with the diagnosis of LSIL in 5 women (29.4\% of all positive tests for high-risk HPV types), HSIL in 3 women(17.6\% of all positive tests for high-risk HPV types), and ASCUS in 1 woman ( $6 \%$ of all positive tests for high-risk HPV types). The positivity for high-risk HPV types in women with NILM and intraepithelial lesions (LSIL, HSIL, and ASCUS) was approximately equal.

The analysis of the presence of positive tests for hrHPV types in women with dysplasia, depending on the LBC diagnosis, found that positive and negative results occur with approximately the same frequency. In women with LSIL, there were 5 with positive results and 5 with negative results, In women with HIS, there were 3 with positive and 2 with negative results. Analysis of the distribution of HPV positivity for hrHPV types showed that HPV type 16 was the most common, which was found in 7 patients (36.8 of all positive HPV tests). The next most common type was type 51, found in 4 women (21\% of all positive HPV tests). Two types of viruses were detected in 6 women (31.5\% of all positive HPV tests). These women had combinations the following types: 16 and 51, 16 and 39, 68 and 39, 31 and 53, 51 and 73, and 31 and 58. The frequency of distribution of other types $(39,68,31,52$, 73,58 , and 18 ) varied from $10.5 \%$ to $5.2 \%$ (Fig.2).

The frequency of HPV detection depending on age showed that the maximum incidence of HPV in samples was significantly more frequent at the age of 25-45 years- 15 cases (78.9\% of all positive HPV tests) $(P<0.001)$. It characterizes the immune status of this age group, and in most cases, it is transient. Approximately $70 \%$ of young women have HPV infection that disappears 12 months after detection. Long-term preservation of HPV is mainly associated with hrHPV types (mainly, types 16 and 18). ${ }^{(20)}$ In women 46 years and older, signs of HPV infection were less common and accounted for 4 cases $(21 \%)$.

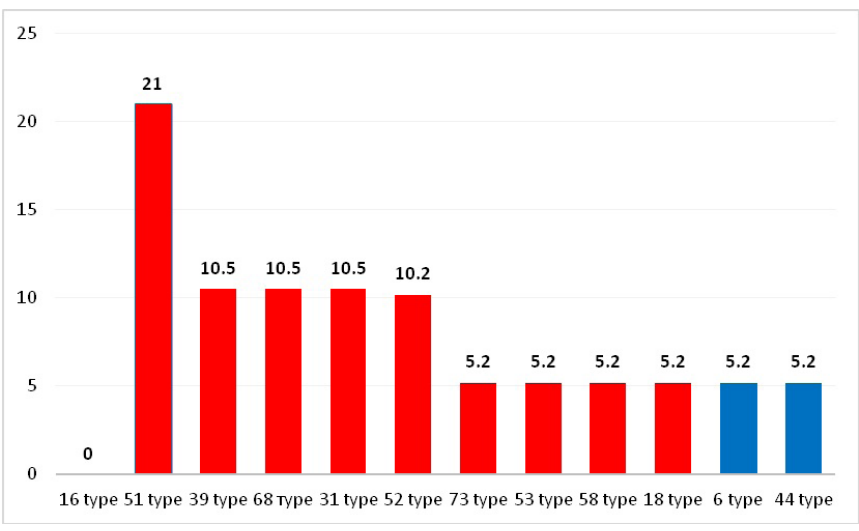

Fig.2. Frequency of distribution of HPV types (\%)

Thus, the analysis of cytological samples by the LBC method in women of $\mathrm{RS}(\mathrm{Y})$ revealed a high prevalence of NILM in the samples to compare with intraepithelial lesions of the cervix. Among intraepithelial lesions, LSIL was significantly more common.

Positive HPV tests were observed in less than half of the cases. The vast majority of positive HPV tests were hrHPV types, and 16 and 51 types marked the most frequent. The positive tests for hrHPV types in women with NILM and intraepithelial lesions (LSIL, HSIL, and ASCUS) were approximately equal. The frequency of positive tests for hrHPV types in women under 45 was higher than in women 46 years and older.

In conclusion, since each stage of morphological research has not only some capabilities, but also limitations, it dictates the need to use methods of complex diagnostics. The combined use of LBC and HPV testing for hrHPV infection improves the effectiveness of diagnostics by reducing the amount of uninformative material and allows detecting pathological changes at an earlier stage. Such a combined approach significantly increases the value of diagnostic measures and will expand the capabilities of the cytologist in diagnosing and giving recommendations for clinical practice.

\section{Competing Interests}

The authors declare that they have no competing interests.

\section{References}

1. Zubritsky MG, Yakoltsevich MI, Tingaeva ER, Aniskevich AA, Lazarevich NA, Basinskiy VA. [Human papillomavirus and cervical cancer]. Journal of the Grodno State Medical University. 2009;(1):18-22. [Article in Russian].

2. Wheeler CM, Hunt WC, Schiffman M, Castle PE; Atypical Squamous Cells of Undetermined Significance/LowGrade Squamous Intraepithelial Lesions Triage Study Group. Human papillomavirus genotypes and the cumulative 2-year risk of cervical precancer. J Infect Dis. 2006;194(9):12911299. doi:10.1086/507909 
3. Liu Y, Pan Y, Gao W, Ke Y, Lu Z. Whole-Genome Analysis of Human Papillomavirus Types 16, 18, and 58 Isolated from Cervical Precancer and Cancer Samples in Chinese Women. Sci Rep. 2017;7(1):263. Published 2017 Mar 21. doi:10.1038/s41598-017-00364-9

4. Bernard HU, Burk RD, Chen Z, van Doorslaer K, zur Hausen H, de Villiers EM. Classification of papillomaviruses (PVs) based on $189 \mathrm{PV}$ types and proposal of taxonomic amendments. Virology. 2010;401(1):70-79. doi:10.1016/j. virol.2010.02.002

5. Rogovskaya SI. Papillomavirus infection in women and cervical pathology: to help a practitioner. 2nd ed. M.: GEOTAR-Media; 2008. [In Russian].

6. Prilepskaya VN, Bayramova GR, Kogan EA, Chernova VF, Okushko AA. [New opportunities for early diagnosis and prevention of HPV-associated cervical lesions]. MC. 2015. №XX. URL: https://cyberleninka.ru/article/n/novye-vozmozhnostiranney-diagnostiki-i-profilaktiki-vpch-assotsiirovannyhporazheniy-sheyki-matki. [Article in Russian].

7. Li N, Franceschi S, Howell-Jones R, Snijders PJ, Clifford GM. Human papillomavirus type distribution in 30,848 invasive cervical cancers worldwide: Variation by geographical region, histological type and year of publication. Int J Cancer. 2011;128(4):927-935. doi:10.1002/ijc.25396

8. Burk RD, Chen Z, Van Doorslaer K. Human papillomaviruses: geneticbasisofcarcinogenicity.PublicHealth Genomics. 2009;12(5-6):281-290. doi:10.1159/000214919

9. Smith JS, Lindsay L, Hoots B, et al. Human papillomavirus type distribution in invasive cervical cancer and highgrade cervical lesions: a meta-analysis update. Int J Cancer. 2007;121(3):621-632. doi:10.1002/ijc.22527

10. Gudz OV, Kamilova IK, Miklin OP. [HPV infection of the cervix uteri: Prospects for combination treatment]. Russian Bulletin of Obstetrician-Gynecologist. 2016;(2):99-103. [Article in Russian].

11. Novik VI. [Epidemiology of cervical cancer, risk factors, screening]. Practical Oncology. 2002;3(3):156-165. [Article in Russian].

12. Kedzja W. Analiza czynnikow komorkowych i ustrojowych w procese kancerogenezy komorek nablonka paraepidermalnego szyjki macicy zakazonych wirusem brodawczaka ludzskego. Poznan: Wydawnictwo Naukowe; 2003.

13. Shabalova IP. Cytological atlas. Criteria for the diagnosis of cervical diseases. M.: Triad-X; 2001.[In Russian].

14. Zaravinos A, Mammas IN, Sourvinos G, Spandidos DA. Molecular detection methods of human papillomavirus (HPV). Int J Biol Markers. 2009;24(4):215-222. doi:10.5301/ jbm.2010.754

15. Dobrokhotova YuE, Venediktova MG, Sarantsev AN, Morozova KV, Suvorova VA. [A modern approach to the treatment of moderate to severe cervical dysplasia against the background of human papillomavirus using antiviral therapy]. Lechebnoe Delo. 2016;(4). URL: https://cyberleninka. $\mathrm{ru} /$ article/n/sovremennyy-podhod-k-lecheniyu-displaziiepiteliya-sheyki-matki-umerennoy-i-tyazheloy-stepeni-nafone-virusa-papillomy-cheloveka-s. [Article in Russian].

16. Sherman ME, Lorincz AT, Scott DR, et al. Baseline cytology, human papillomavirus testing, and risk for cervical neoplasia: a 10-year cohort analysis. J Natl Cancer Inst. 2003;95(1):46-52. doi:10.1093/jnci/95.1.46

17. Hoyer H, Scheungraber C, Kuehne-Heid R, et al. Cumulative 5-year diagnoses of CIN2, CIN3 or cervical cancer after concurrent high-risk HPV and cytology testing in a primary screening setting. Int J Cancer. 2005;116(1):136143. doi:10.1002/ijc.20955

18. Petry KU, Menton S, Menton M, et al. Inclusion of HPV testing in routine cervical cancer screening for women above 29 years in Germany: results for 8466 patients. Br J Cancer. 2003;88(10):1570-1577. doi:10.1038/sj.bjc.6600918

19. The Bethesda System for Reporting Cervical Cytology: Definitions, Criteria, and Explanatory Notes. 3rd Edition. Nayar R, Wilbur David C, editors. Springer International Publishing Switzerland; 2015.

20. Krasnopolsky VI, Serova OF, Tumanova VA, Zarochentseva NV, Melnik TN, Lipovenko LN, Pozdnyakova TI. [Impact of infections on the female reproductive system]. Russian Bulletin of Obstetrician-Gynecologist. 2004;4(5):2629. [Article in Russian]. 